\title{
Processo de Inclusão em uma Escola de Ensino Regular do Município de Nova Olinda-Ceará
}

Inclusion Process in a Regular School of Education in the City of Nova Olinda-Ceará

Proceso de inclusión en una escuela regular de educación de la ciudad de Nova Olinda-Ceará

Eliane de França Sobrinho

ORCID: https://orcid.org/0000-0002-5939-0889 Universidade Regional do Cariri, Brasil

E-mail:elianefrancadan@gmail.com

Dennis Bezerra Correia

ORCID: https://orcid.org/0000-0002-7782-4767

Universidade Regional do Cariri, Brasil

E-mail: denniscorreia40@gmail.com

Cícero Jorge Verçosa

ORCID: https://orcid.org/0000-0002-3284-6719

Secretaria de Educação e Esportes de Pernambuco, Brasil

E-mail: cjvercosa@hotmail.com

Francisca Sâmara Muniz dos Santos

ORCID: https://orcid.org/0000-0003-0443-217X

Universidade Regional do Cariri, Brasil

E-mail:samara10muniz@yahoo.com

Rafael Henrique Luciano dos Santos

ORCID: https://orcid.org/0000-0001-6968-6803

Secretaria de Educação e Esportes de Pernambuco, Brasil E-mail: rafaelhenrique.bio@gmail.com

Ginna Gonçalves Pereira

ORCID: https://orcid.org/0000-0002-0267-2615 Universidade Regional do Cariri, Brasil E-mail: ginna.pereira@urca.br

Jamile Maria Pereira Bastos Lira de Vasconcelos

ORCID: https://orcid.org/0000-0001-5135-902X Secretaria de Educação e Esportes de Pernambuco, Brasil E-mail: jamilebastoslira@gmail.com

Filipe Gutierre Carvalho de Lima Bessa

ORCID: https://orcid.org/0000-0001-8126-8831

Universidade Estadual Vale do Acaraú, Brasil

E-mail: filipe_carvalho@uvanet.br

Francileide Vieira Figueirêdo

ORCID: https://orcid.org/0000-0002-6853-854X

Universidade Regional do Cariri, Brasil

E-mail: francileidevf@gmail.com

Rivânia Silva Alves

ORCID: https://orcid.org/0000-0003-1434-8086

Universidade Regional do Cariri, Brasil

E-mail: rivaniasalves@yahoo.com.br

Francisco Diego Pereira

ORCID: https://orcid.org/0000-0002-4816-3381

Universidade Regional do Cariri, Brasil

E-mail: diego.vilar.pereira@gmail.com

José Aglailson Oliveira da Anunciação

ORCID: https://orcid.org/0000-0003-1751-2953

Universidade Regional do Cariri, Brasil E-mail: aglailsonoliveira@gmail.com

Annayara Suyane Oliveira da Silva

ORCID: https://orcid.org/0000-0001-5135-902X

Secretaria de Educação e Esportes de Pernambuco, Brasil

E-mail: annayaerasuyane@hotmail.com

Clêidio da Paz Cabral

ORCID: https://orcid.org/0000-0003-1825-4925

Secretaria de Educação e Esportes de Pernambuco, Brasil

E-mail: cabralbahia@hotmail.com

Luiz Neldecílio Alves Vitor

ORCID: https://orcid.org/0000-0003-4085-4214

Secretaria de Educação e Esportes de Pernambuco, Brasil

E-mail: professorluizneldecilio@gmail.com 


\author{
Allyson Francisco dos Santos \\ ORCID: https://orcid.org/0000-0001-8635-6398 \\ Secretaria de Educação e Esportes de Pernambuco, Brasil \\ E-mail: allysons@outlook.com.br \\ Jailson Renato de Lima Silva \\ ORCID: https://orcid.org/0000-0003-1292-8060 \\ Universidade Regional do Cariri, Brasil \\ E-mail: jailsonslrj@outlook.com \\ João Eudes Lemos de Barros \\ ORCID: https://orcid.org/0000-0003-1829-795X \\ Universidade Regional do Cariri, Brasil \\ E-mail: joao.eudeslemos@urca.br \\ Luiz Marivando Barros \\ ORCID: https://orcid.org/0000-0003-2314-1167 \\ Universidade Regional do Cariri, Brasil \\ E-mail: lmarivando@hotmail.com \\ Geórgia Maria de Alencar Maia \\ ORCID: https://orcid.org/0000-0002-1125-6410 \\ Universidade Regional do Cariri, Brasil \\ E-mail: georgia.alencar@hotmail.com \\ Maria Iderlânia de Freitas Sousa \\ ORCID: https://orcid.org/0000-0001-9657-8904 \\ Universidade Regional do Cariri, Brasil \\ E-mail: iderbio@hotmail.com \\ Elizângela Beneval Bento \\ ORCID: https://orcid.org/0000-0002-7516-9711 \\ Universidade Regional do Cariri, Brasil \\ E-mail: elizangelaeliz@yahoo.com.br
}

\title{
Resumo
}

O presente trabalho focaliza o tema da inclusão de alunos com necessidades especiais no processo ensino aprendizagem no contexto escolar do ensino regular. Configura em uma reflexão sobre a educação inclusiva, fazendo uma breve análise do histórico do processo da inclusão dessas crianças na escola. Dessa forma trata-se de uma pesquisa bibliográfica que teve como temática central discutir o desafio da inclusão no ambiente escolar, e da reorganização da educação especial e refletindo sobre a importância de uma formação docente que contribua para o desenvolvimento de uma educação que respeite a diversidade. Abordar a trajetória histórica da educação das pessoas com necessidades educacionais especiais, desde os atendimentos segregativos até os processos inclusivos, apresentando alguns conceitos necessários à compreensão do que é educação especial e sobre como são identificados quadros que constituem sujeitos atendidos pela educação especial. Os resultados apontam que, o atendimento educacional especializado tem como função identificar, elaborar e organizar recursos pedagógicos e de acessibilidade que eliminem as barreiras para a plena participação dos alunos, considerando suas necessidades específicas.

Palavras-chave: Educação inclusiva; Pessoa Com Deficiência - PCD; Formação docente.

\begin{abstract}
This paper focuses on the inclusion of students with special needs in the teaching-learning process in the school context of regular education. It configures a reflection on inclusive education, making a brief analysis of the history of the process of including these children in school. Thus, this is a bibliographic research whose main theme was to discuss the challenge of inclusion in the school environment, and the reorganization of special education and reflecting on the importance of teacher education that contributes to the development of an education that respects diversity. To approach the historical trajectory of the education of people with special educational needs, from the segregative attendances to the inclusive processes, presenting some concepts necessary for the understanding of what is special education and about how are identified frames that constitute subjects attended by the special education. The results indicate that the specialized educational service has the function of identifying, elaborating and organizing pedagogical and accessibility resources that eliminate the barriers to the full participation of the students, considering their specific needs.
\end{abstract}

Keywords: Inclusive education; Person With Disabilities - PWD; Teacher Training.

\section{Resumen}

Este trabajo se centra en el tema de incluir a los estudiantes con necesidades especiales en el proceso de enseñanzaaprendizaje en el contexto escolar de la educación regular. Representa una reflexión sobre la educación inclusiva, haciendo un breve análisis de la historia del proceso de inclusión de estos niños en la escuela. Por tanto, es una investigación bibliográfica quesu tema central fue discutir el desafío de la inclusión en el ámbito escolar, y la reorganización de la educación especial, y reflexionar sobre la importancia de la formación docente que contribuya al desarrollo de una educación respetuosa con la diversidad. Abordar la trayectoria histórica de la educación de personas con necesidades educativas especiales, desde los servicios de segregación hasta los procesos inclusivos, presentando 
algunos conceptos necesarios para entender qué es la educación especial y cómo se identifican los marcos que constituyen las asignaturas atendidas por la educación especial. Los resultados muestran que el servicio educativo especializado tiene la función de identificar, desarrollar y organizar recursos pedagógicos y de accesibilidad que eliminen barreras para la plena participación de los estudiantes, considerando sus necesidades específicas.

Palabras clave: Educación inclusiva; Persona Con Discapacidades - PCD; Formación de professores.

\section{Introdução}

O processo de inclusão trata de envolver um indivíduo dentro de uma atividade ou assunto, buscando a melhoria na qualidade de vida de todos os tipos de pessoas com ou sem deficiência. Numa sociedade devemos levar em conta que as diferenças e convivências com cada um nos leva a refletir sobre a valorização da diversidade buscando preparar-se para uma mudança. De fato, entende-se que cada ser humano é uno, e as oportunidades devem ser iguais para todos (Aguiar, 2021).

Nas escolas regulares o sistema de ensino compreende em formar jovem aprendiz favorecendo uma pequena parte dos alunos ali envolvidos. A falta de profissionais capacitados para atender os diferentes tipos de alunos e suas dificuldades faz com que eles sejam mantidos em espaços especializados, pois independente da capacidade de cada aluno a escola deve garantir seu acesso e participação (Kistt \& Gonçalves, 2021). Segundo Leite (2018), a palavra inclusão nos dias de hoje tem como objetivo definir igualdade, direitos e fraternidade. Coisas que dificilmente sabemos colocar em prática em nossas vidas.

Uma pessoa com deficiência merece sim uma atenção especial, mas isso não pode ser motivo para excluí-la. O acesso às escolas regulares trará à criança a oportunidade de conviver com muitas pessoas diferentes e novos conhecimentos, isso mostrará que apesar de uma dificuldade ela pode sim seguir em frente, brincar, ter um futuro brilhante, ser um ótimo profissional e acima de tudo ser muito feliz, além de ser um aprendizado também para as crianças "normais" mostrando-lhes que o mundo é para todos e que merecem o devido respeito, que as dificuldades e diferenças não podem ser limitações em nossas vidas. (Silva \& Faria, 2018).

A escola inclusiva é aquela que abre espaço para todas as crianças, incluindo as que apresentam necessidades especiais. As crianças com deficiência têm direito à educação em escola regular (Almeida \& Montino, 2021). No convívio com todos os alunos, a criança com deficiência deixa de ser "segregada" e sua acolhida pode contribuir muito para a construção de uma visão inclusiva, e garantir que o processo de inclusão possa fluir da melhor maneira é responsabilidade de todos (Souza \& Miranda, 2020).

Apesar da inclusão de alunos com deficiência na rede regular de ensino ser um direito garantido pela constituição federal, para que ela realmente se efetive é necessário que a comunidade escolar esteja preparada para esta mudança. A inclusão apoia e defende a participação de todo o universo escolar, professores, diretores, funcionários, alunos e comunidade. O sucesso da inclusão está diretamente ligado ao trabalho desenvolvido por toda comunidade escolar (França, 2021).

Conforme Dias e Leventhal (2021) para que as escolas se tornem inclusivas é preciso que seus funcionários, desde a limpeza até a direção, assumam seus conhecimentos e práticas, e não coloquem a diferença como um obstáculo, mas sim como um desafio que vão enfrentar e ganhar, com novas ideias, perspectivas de trabalho para estar preparados, onde os alunos passam a ter direito de aprendizagem iguais aos outros, para isso é importante que tenham conhecimento e condições para aplicá-lo no dia a dia da escola.

$\mathrm{O}$ atendimento de pessoas com N.E.E. na rede regular de ensino exige dos seus profissionais conhecimentos produzidos em diferentes áreas (psicologia, medicina, pedagogia, arquitetura etc.) para gerar um saber interdisciplinar, indispensável ao sucesso da integração. Uma das perguntas a se responder é se os profissionais da educação foram especializados suficientemente para promover a inclusão de pessoas com N.E.E. às classes regulares (Souza \& Souza, 2018). Na escola atual vem crescendo o número de crianças com deficiência, e muitas vezes os educadores não sabem lidar com elas. Atualmente, apesar de se ter uma política de inclusão, por qual razão as pessoas com deficiência continuam excluídas? 
A importância de discutir e refletir sobre esta temática se justifica pelo fato de que, para as pessoas com deficiência, a inclusão não é uma realidade em todas as escolas, sejam elas públicas ou privadas. O meio escolar tem que passar por melhorias para repensar o ensino para estes alunos, para que os mesmos percebam que estão sendo valorizados, respeitados e aceitados no ambiente escolar (Santos et al, 2020).

Assim, este trabalho justifica-se como uma perspectiva de reflexão e auxilio para o trabalho docente, buscando refletir sobre os desafios e dificuldades da inclusão dos alunos com necessidades educativas especiais, nos levando a repensar o histórico da proposta da escola inclusiva, discutindo sobre a reorganização da educação especial e refletindo sobre a importância de uma formação docente que contribua para o desenvolvimento de uma educação que respeite a diversidade.

\section{Inclusão Escolar}

Entende-se por inclusão o direito, a todos, do alcance continuado ao lugar comum da vida em comunidade, comunidade essa que deve estar orientada por ações de acolhimento à diversidade humana, de aceitação das diferenças individuais, de esforço coletivo na equiparação de oportunidades de desenvolvimento, com qualidade, em todas as dimensões da vida (Calmon, 2018).

A escola comum se torna inclusiva quando reconhece as diferenças dos alunos diante do processo educativo e busca a participação e o progresso de todos, adotando novas práticas pedagógicas. Não é fácil e imediata a adoção dessas novas práticas, pois ela depende de mudanças que vão além da escola e da sala de aula. Para que essa escola possa se concretizar, é patente a necessidade de atualização e desenvolvimento de novos conceitos, assim como a redefinição e a aplicação de alternativas e práticas pedagógicas e educacionais compatíveis com a inclusão (Cabral \& Almeida, 2019).

Um ensino para todos os alunos há que se distinguir pela sua qualidade, o desafio de fazê-lo acontecer nas salas de aulas é uma tarefa a ser assumida por todos os que compõem um sistema educacional. Um ensino de qualidade provém de iniciativas que envolvem professores, gestores, especialistas, pais e alunos e outros profissionais que compõem uma rede educacional em torno de uma proposta que é comum a todas as escolas e que, ao mesmo tempo, é construída por cada uma delas, segundo as suas peculiaridades (Winter \& Monzón, 2020).

Nas escolas inclusivas, a qualidade do ensino não se confunde com o que é ministrado nas escolas-padrão, consideradas como as que melhor conseguem expressar um ideal pedagógico inquestionável, medido e definido objetivamente e que se apresentam como modelo a ser seguido e aplicado em qualquer contexto escolar. As escolas-padrão cabem na mesma lógica que define as escolas dos diferentes, em que as iniciativas para melhorar o ensino continuam elegendo algumas escolas e valorandoas positivamente, em detrimento de outras (Lima et al, 2020).

Cada escola é única e precisa ser, como os seus alunos, reconhecida e valorizada nas suas diferenças (Bistaffa et al, 2021). A inclusão é formada por um conjunto, coordenado por serviços tanto sociais como educacionais e em outras áreas dando suporte nos serviços de assistencialismo (Menicucci \& Gomes, 2018).

\section{O processo de inclusão/ escola inclusiva}

A declaração de Salamanca defende a ideia de que todos os alunos, sempre que possível, devem aprender juntos independentemente de suas condições. Ao mesmo tempo, ela aponta a escolarização de crianças o que deu início a educação inclusiva, nos casos em que a educação regular não pode satisfazer às necessidades educativas ou sociais do aluno. No entanto, a Declaração de Salamanca trouxe um avanço importante ao chamar atenção dos governantes para a necessidade de aplicar todo investimento possível para o redimensionamento das escolas, para que possam atender com qualidade, a todas as crianças independente de suas diferenças e/ou dificuldades (Vieira \& Carmo 2017).

Dessa forma a inclusão educacional escolar, no Brasil, é uma ação política, cultural, social e pedagógica que visa garantir o direito de todos os alunos de estarem juntos, aprendendo e participando (Ferreira \& Bobato, 2021). Partindo desta afirmação 
sobre a inclusão, podemos entender que a Educação Inclusiva, não está somente pautada para o aluno com deficiência, funcionando como um modelo educacional para uma escola livre de preconceitos.

O movimento pela educação inclusiva no Brasil teve um grande impacto na discussão de políticas educacionais para crianças e adolescentes com deficiência uma vez que a grande maioria desta população havia sido historicamente excluída do sistema educacional público brasileiro (Santos, 2017).

Brancher e Camargo (2019), enfocam que, em 1994, a declaração de Salamanca esboçou adequações para a Inclusão de alunos com necessidades educacionais especiais na escola regular. Mais uma vez a comunidade internacional se faz presente e apoia a iniciativa. Assim, o movimento pela inclusão cresceu e se consolidou ao longo do século XX, buscando garantir processos educacionais democráticos inclusivos, preocupados em garantir direitos iguais a todos os cidadãos, independentemente de suas características individuais (Vieira \& Nogueira, 2017).

A educação especial é fruto da mudança de concepção de sociedade, do avanço das políticas públicas e dos movimentos sociais que pressionam o Estado na viabilização de seus direitos como sujeitos sociais e a formação de profissionais da educação, principalmente dos professores, também é influenciada pelas mudanças ocorridas na coletividade, no universo do trabalho e na economia do país (Correia, 2014).

Nos últimos anos, as políticas de educação inclusiva no Brasil tiveram um avanço significativo em termos de conquistas e regulamentação de direitos construídos pelo segmento das pessoas com deficiência. Na perspectiva da inclusão, a Educação Especial passa a integrar a proposta pedagógica da escola, promovendo o atendimento às necessidades educacionais especiais de alunos com deficiência, transtornos globais de desenvolvimento e altas habilidades/superdotação (Lina \& Barros, 2017).

A educação é um direito de todos e dever do Estado e da família. Assim começa o art. 205 da Constituição Federal de 1988. Este princípio fundamenta a trajetória de lutas pelo direito à educação das pessoas com deficiência e ganha mais força em 2015, com a Lei Brasileira de Inclusão, Lei n. 13.146/2015, também denominada como Estatuto da Pessoa com Deficiência (Teixeira et al, 2020).

Inclusão Escolar, na atualidade, está mais relacionada a preocupação de que todas as crianças com deficiência estejam inseridas na escola regular, do que ações que orientem como a inclusão deverá ser realizada. Quando se fala em inclusão, não se deve pensar somente no aluno com deficiência e sim na própria escola lidando com o que é diferente, ou seja, diferente de um padrão antes já definido (Rocha et al, 2018).

\section{Alunos especiais}

Desde o começo da história, durante séculos, a deficiência no Brasil já obteve diversos termos. Rabelo e Kassar (2018), sustenta a ideia de que o termo "pessoas com necessidades especiais" surgiu justamente para substituir "deficiência" por "necessidades especiais", daí a expressão "portadores de necessidades especiais". De início, passou a representar apenas um novo termo, após a vigência da Resolução CNE/CEB n 2, de 11 de setembro de 2001, o termo "necessidades especiais" passou a ter um valor agregado tanto à pessoa que tinha deficiência quanto também às pessoas que não tinham deficiência.

A declaração de Salamanca utiliza o termo N.E.E. para representar todas as pessoas que possuem uma elevada capacidade ou dificuldades de aprendizagem. Assim, o grupo de pessoas com N.E.E. compreende desde alunos com alguma deficiência perene, até aqueles que têm resultados abaixo da média no seu processo de ensino e aprendizagem não associados à deficiência e sim às dificuldades de aprendizagem (Rodrigues \& Moreira, 2019).

De acordo com Canto e Silva (2021), as pessoas com N.E.E. são aqueles que possuem dificuldades de aprendizagem, disfunções comportamentais, deficiência física não sensorial, deficiência mental, deficiências múltiplas, deficiência física sensorial (cegos, surdos e surdos-cegos) e altas habilidades (superdotação). Vale ressaltar que as pessoas com autismo e transtorno de déficit de atenção com hiperatividade (TDAH) também compõem esse grupo de pessoas que precisam de uma 
assistência educacional singular.

Assim, o termo N.E.E. é muito abrangente, uma vez que não envolve apenas alunos com deficiência, mas todos aqueles que necessitam, em algum momento de sua vida, de um apoio educacional (Sousa et al, 2021).

Para as escolas os alunos ditos como deficientes são aqueles que apresentam algum tipo de deficiência física ou mental, transtornos ou dificuldades de aprendizagem e/ou de comunicação. Há vários tipos de deficiência física e mental, entre elas podemos citar as mais frequentes nas escolas, regulares do município de Nova Olinda, a maioria das crianças acompanhadas possuem as seguintes deficiências:

O Transtorno do Déficit de Atenção e Hiperatividade (TDAH): Transtorno neurobiológico que aparece na infância e que na maioria dos casos acompanha o indivíduo por toda a vida. O TDAH (CID-10, F90) se caracteriza pela combinação de sintomas de desatenção, hiperatividade (inquietude motora) e impulsividade sendo a apresentação predominantemente desatenta conhecida por muitos como DDA (Distúrbio do Déficit de Atenção) (Silva \& Cabral, 2020).

Síndrome Down: condição genética que leva a características físicas singulares e propensão a algumas doenças. Ela é chamada de trissomia 21 e causada por um cromossomo extra no par 21. (Viana, M. N. G. et al, 2020). Embora apresentem deficiências intelectuais e de aprendizado, pessoas com síndrome de Down têm personalidade única, estabelecem boa comunicação e também são sensíveis e interessantes. Quase sempre, quanto maior o estímulo dado a essas crianças durante a infância, menor o "grau" de presença dos sintomas (Cazarotti \& Ribeiro, 2018).

Transtorno Opositivo-Desafiador (TOD): condição responsável por comportamentos que são completamente restritivos em ambientes sociais. As crianças e os adolescentes incluídas nesse quadro costumam manifestar momentos de raiva, insubordinação, teimosia constante, hostilidade, sentimento de vingança e uma grande dificuldade em obedecer a regras quando solicitadas (Araújo \& Araújo, 2017).

Autismo ou Transtorno do Espectro Autista (TEA): caracterizado como uma síndrome comportamental que compromete o desenvolvimento ao longo da vida. As principais alterações identificadas são o déficit nas áreas de comunicação e socialização, padrões restritos e repetitivos de comportamento, interesses ou atividades (Pimenta, 2019).

Microcefalia: malformação congênita em que o cérebro não se desenvolve de maneira adequada. Essa malformação pode ser efeito de uma série de fatores de diferentes origens, como substâncias químicas e infecciosas, além de bactérias, vírus e radiação. A microcefalia pode ser acompanhada de epilepsia, paralisia cerebral, retardo no desenvolvimento cognitivo, motor e fala, além de problemas de visão e audição (Santos et al, 2017).

A escola onde foi realizado a pesquisa possui ao todo 21 alunos tidos como especiais, onde os mesmos possuem as seguintes deficiências, autismo, déficit de aprendizagem e TDAH, porem foi informado que a escola possui uma demanda maior, mais não foi possível especificar o tipo de deficiência que esses alunos possuem, pois, os mesmos não têm laudo médico.

\section{Metodologia}

\section{Tipo de pesquisa}

Este trabalho foi realizado através de uma pesquisa qualitativa/quantitativa (Schneider, 2017) feita em duas etapas. A primeira etapa em uma pesquisa bibliográfica com o objetivo central de realizar uma análise e reflexão da inclusão de crianças com deficiência nas escolas regulares , a segunda envolveu a realização de uma pesquisa de campo (Estrela, 2018) em uma das escolas da rede municipal do município de Nova Olinda, visando o entendimento de como se dá a política de educação inclusiva nesse município, e se a escola se encontra preparada para receber estas crianças, por meio da acessibilidade, e também se os funcionários dessa instituição estão preparados para atendê-los, e neste aspecto promove-se a discussão sobre as dificuldades encontradas pelo aluno com este perfil. 
Figura 1. Questionário semiestruturado aplicado aos docentes da E.E.F. Padre Cristiano Coelho em Nova Olinda-CE.

\section{QUESTIONARIO}

1. Você considera a escola adequada para as crianças portadoras de necessidades especiais?
( ) $\operatorname{sim}$
( ) não

2. Você considera que o atendimento feito na sala do $\mathrm{AEE}$ é suficiente para à aprendizagem e desenvolvimento desses alunos?
( ) $\operatorname{sim}$
( ) não

3. Na sua opinião a convivência dos alunos com necessidades especiais com os demais alunos ditos normais, em sala de aula, contribui para seu desenvolvimento?
( ) $\operatorname{sim}$
( ) não

4. Você se considera preparado para trabalhar com crianças com necessidades especiais?
( ) $\operatorname{sim}$
( ) não

5. Você recebeu formação para trabalhar com essas crianças?
( ) $\operatorname{sim}$
( ) não

6. A escola que você trabalha disponibiliza material adequado para trabalhar com essas crianças?
( ) $\operatorname{sim}$
( ) não

7. Quais tipos de deficiências possuem os alunos da escola que você trabalha?

8. Quantos alunos portadores de deficiência estudam na escola que você trabalha?

9. Quais as principais dificuldades você percebe/sente para incluir o aluno com deficiência no cotidiano escolar?

10. O que você propõe para melhorar a inclusão e a aprendizagem dos alunos com deficiência na atividade escolar?

Fonte: Autores.

Este trabalho também seguiu os preceitos do estudo de caráter exploratório, por meio de uma pesquisa bibliográfica, que, segundo (Brigagão, 2019), "é desenvolvida a partir de material já elaborado, constituído de livros e artigos científicos". Nesta perspectiva as fontes utilizadas foram artigos científicos produzidos no Brasil e publicados, por intermédio de uma busca feita na internet sobre a temática abordada.

Inicialmente, realizou-se estudos com base na bibliografia específica a fim de se inteirar sobre a temática e identificar suas bases conceituais para, assim, elaborar o instrumento para coleta das informações, bem como o referencial teórico. Com a pesquisa delineada, procurou-se a direção da escola pretendida para o estudo e os professores, para a qual se apresentou os objetivos e possíveis contribuições da mesma, bem como os procedimentos para coleta dos dados junto aos mesmos.

\section{Instrumentos de Coleta de Dados}

A coleta de dados na pesquisa bibliográfica foi realizada através de livros, documentos e artigos eletrônicos, e através de uma pesquisa de campo realizada na escola regular do município de Nova Olinda, essa teve início após uma seleção das escolas que vem atendendo alunos N.E.E, após a seleção foi realizado um estudo de caso, onde foi aplicado um questionário aos professores dessa instituição.

Dos 29 (vinte nove) professores que atuam na escola, 10 (dez) docentes responderam ao questionário, sendo 8 do sexo feminino e 2 do sexo masculino. Dos 10 professores que receberam o questionário, apenas 8 devolveram devidamente 
preenchido, porém isso não prejudicou o levantamento dos dados.

O questionário foi composto por 10 questões (Figura 1) e apresentou perguntas fechadas que indicam duas opções se limitando apenas a posição afirmativa ou negativa e questões abertas onde os professores poderão expressar suas opiniões e sugestões a respeito da escola e do atendimento feito aos alunos portadores de necessidades especiais. Os mesmos ministram aulas nas salas de $5^{\circ}, 6^{\circ}$ e $7^{\circ}$ ano do ensino fundamental, e sem se identificar nos forneceram informações valiosas para o desvelamento desta pesquisa. Para não expor o nome dos professores participantes da pesquisa, foram denominados P1, P2, P3, P4, P5, P6, P7, P8, P9 e P10. Os procedimentos para a coleta dos dados foram feitos individualmente, dando um prazo considerável e pré-determinado para o docente responder e entregar o material.

Para análise dos dados deste trabalho, compreendemos primeiramente a trajetória histórica da educação especial, destacando alguns conceitos necessários à compreensão do que é educação especial, pesquisando como se dá o processo de formação dos professores, traçando assim, o perfil da política de inclusão desenvolvida no município de Nova Olinda -CE.

\section{Aspectos éticos da pesquisa}

Atendendo aos aspectos éticos, todos os sujeitos foram devidamente esclarecidos acerca dos objetivos e possíveis contribuições da pesquisa, enfatizando-se sua participação como voluntária, destacando a livre opção em aceitar ou não participar, e assegurando-se a privacidade de sua identidade em todas as etapas da pesquisa, condicionando sua participação à assinatura do Termo de Consentimento Livre e Esclarecido - TCLE (ANEXOS), conforme preconiza a Resolução 510/2016 do Conselho Nacional de Saúde (CNS).

Houve o comprometimento em citar os nomes dos autores utilizados no estudo respeitando a norma brasileira regulamentadora 6023 que dispõe sobre os elementos a serem incluídos e orienta a compilação e produção de referências. Os dados coletados foram utilizados exclusivamente com a finalidade cientifica.

\section{Resultados e Discussão}

Quando questionados aos professores se eles consideravam a escola adequada para as crianças portadoras de necessidades especiais. Os professores P2, P3 e P4, responderam que sim os demais disseram que não. P1 disse "não, há anos se fala em salas adequadas a essas crianças, porém não há equipamentos e atividades necessárias a essa demanda". Já P3 disse "sim, pois atende as condições necessárias".

Sunde (2018), traz uma contribuição interessante a respeito desse assunto quando explica que a escola, longe de ser igualitária, acentua a desigualdade favorecendo apenas alguns poucos possuidores de uma "herança cultural" semelhante a que lhe é própria, reforçando a estrutura e estratificação de classes sociais, uma vez que são predominantes os valores burgueses de ascensão social - o esforço de cada indivíduo, que não contam com uma infraestrutura escolar adequada as suas necessidade, e cujos talentos e méritos próprios o possibilitam chegar ou não à escala de ascensão social. Este é o discurso corrente internalizado pela sociedade, o qual responsabiliza o sujeito pelo seu fracasso caso, em seu percurso estudantil, não consiga moldar-se aos padrões de aprendizagem já estabelecidos.

Mudanças no sistema de ensino na década de 1950 ocorreram com o objetivo de acolher a classes que eram consideradas excludentes da sociedade, em nome da "democratização". Desse modo, configura-se um paradoxo: a escola promove o acesso a todos, mas privilegia aqueles que fazem parte da cultura de elite. Assim, a escola não mais exclui de modo explícito, mas implicitamente, isto é, de modo brando em que "estudantes provenientes das famílias mais desprovidas culturalmente têm todas as chances de obter, ao fim de uma longa escolaridade, muitas vezes paga com pesados sacrifícios, um diploma desvalorizado" (Branco, 2021; Oliveira \& Resende, 2020).

É importante entender que receber o aluno com deficiência na sala de aula não significa inclusão, há necessidade do 
preparo do docente para conhecer o tipo de deficiência e a história de vida do aluno, sua relação com seus familiares e viceversa. Oferecer um ambiente adaptado a necessidade do aluno, com infraestrutura adequada para cada tipo de deficiência e necessidade é obrigação do estabelecimento de ensino, bem como saber como trabalhar com outros alunos e com suas famílias, é este o contexto que chamamos inclusivo. Não podemos exigir que o professor esteja preparado. Há ainda a necessidade do envolvimento de gestores, da iniciativa pública e privada, de políticas públicas, de investimento na formação dos envolvidos, trabalho que não se restringe apenas aos professores, mas a todos, sem exceção.

Já em relação ao questionamento feito ao atendimento realizado na sala do AEE, apenas os professores P2, P3 e P4 consideram o mesmo suficiente para a aprendizagem dos alunos, os demais disseram que não. Isso se deve a pouca estrutura da sala do AEE, a falta de material apropriado para deficiências dos alunos, e também de como esses alunos são atendidos na escola, P7 disse o seguinte "Não, porque não possui material adequado para as deficiências, como material lúdico".

Nas Diretrizes da Política Nacional de Educação Especial na Perspectiva da Educação Inclusiva consta que a função do AEE é "[...] identificar, elaborar e organizar recursos pedagógicos e de acessibilidade que eliminem as barreiras para a plena participação dos alunos, considerando suas necessidades específicas" (Possa \& Pieczkowski, 2020) - ou seja, a produção de atividades e providência de materiais pedagógicos que oportunizem ao aluno com deficiência a apropriação do conteúdo.

O motivo principal de o AEE ser realizado na própria escola do aluno está na possibilidade de que suas necessidades educacionais específicas possam ser atendidas e discutidas no dia a dia escolar e com todos os que atuam no ensino regular e/ou na educação especial, aproximando esses alunos dos ambientes de formação comum a todos, mas isso não é o que acontece na escola. A escola não deve ser vista como o local só de inclusão e sim o lugar que irá apoiar essas pessoas com deficiência, ajudando a desenvolver cada uma dentro do limite de cada deficiência, e é de extrema importância que o AEE assuma um compromisso não só com essas pessoas, mas com o sistema educacional e principalmente com a sua vida profissional.

$\mathrm{O}$ atendimento educacional especializado tem como função identificar, elaborar e organizar recursos pedagógicos e de acessibilidade que eliminem as barreiras para a plena participação dos alunos, considerando suas necessidades específicas. As atividades desenvolvidas no atendimento educacional especializado diferenciam-se daquelas realizadas na sala de aula comum, não sendo substitutivas à escolarização. Esse atendimento complementa e/ou suplementa a formação dos alunos com vistas à autonomia e independência na escola e fora dela (Franco \& Schutz, 2020).

Em relação à está preparado, e se recebeu alguma formação para trabalhar com crianças especiais, dos professores entrevistados apenas P4 respondeu que sim, os demais disseram não ter recebido formação e também não se consideram preparados para trabalhar com esse tipo de criança. O professor P5 disse não estar preparado e nem recebeu formação e reforça sua resposta com a seguinte fala "é de estrema importância a capacitação dos profissionais que atuam na área, tendo em vista que apenas o que é visto na graduação dos professores da rede regular não é suficiente para lidar com a classe".

Não adianta colocar essas crianças na escola se não tiver pessoas capacitadas, preparadas para acolhe-las, tanto na escola como na sala de aula (Boldarine \& Valadares 2018) considera que a inclusão não diz respeito a colocar as crianças nas escolas regulares, mas a mudar as escolas para torná-las mais responsivas às necessidades de todas as crianças; diz respeito a ajudar todos os professores a aceitarem a responsabilidade quanto à aprendizagem de todas as crianças nas suas escolas e prepará-los para ensinar aquelas que estão atualmente excluídas por qualquer razão.

Pensando na formação de professores para o trabalho com crianças com deficiência, evocamos Gatti (2008), ao afirmar que, tanto no Brasil quanto nos demais países, a formação continuada se justifica pelas novas exigências da sociedade contemporânea. A proliferação de cursos de formação continuada nos conduz a refletir se eles têm sido capazes de atender às demandas dos profissionais e se suas condições de trabalho são consideradas adequadas.

Ainda que a legislação brasileira apresente uma série de garantias no que concerne à inclusão de jovens com necessidades educacionais especiais no ensino regular (Ferreira \& Bobato,2021; Cardoso et al, 2021), a aplicação prática de tais 
medidas ainda esbarra na falta de recursos e na dificuldade do professor em lidar com estes alunos em sala de aula. Para que se ofereça uma qualidade de vida melhor é necessário oferecer não só a prática pedagógica, mas atender à necessidade de cada um em ambientes integrados, que ofereçam suporte a essas pessoas, os professores precisam ser capacitados para desenvolver melhor suas habilidades profissionais (Silva et al, 2021).

Quando perguntado se a escola disponibiliza material adequado para se trabalhar com essas crianças, apenas P2, P3 e P4 afirmaram que sim os demais afirmaram que a mesma não disponibiliza material adequado. P2 disse "o material disponibilizado não é adequado para se trabalhar com as deficiências dos alunos".

Muito se fala em inclusão, porem para que haja inclusão deve-se ter condições para que ela aconteça. Em geral as escolas não possuem um ambiente favorável a inclusão, os profissionais reclamam das salas de aula superlotadas, materiais de didáticos escassos, ausência de recursos tecnológicos (Ribeiro, 2017).

A educação inclusiva envolve planejamento e investimento de recursos, por tanto exigem o comprometimento dos órgãos governamentais como preparação previa do ambiente escolar, com investimento na infraestrutura e na área pedagógica para receber esses alunos. Na aérea pedagógica deverão possuir material didático adequado, recursos tecnológicos e profissionais qualificados.

Questionados sobre a quantidade de alunos portadores de deficiência que frequentam a escola os professores não souberam informar. Porém foi feito um levantamento junto a coordenação da escola e foi repassado o quantitativo total de alunos portadores de deficiência que frequentam a escola, ao todo são 21 alunos de ambos os sexos, onde sete são acompanhados na sala do AEE, dos outros, quatro são acompanhados por cuidadores e os demais frequentam a sala regular.

Já em relação aos tipos de deficiência que os alunos que frequentam a escola possuem, a maioria dos professores entrevistados não souberam dizer, ou não quiseram responder, apenas P5, P6 e P8 souberam informar os tipos específicos de deficiência que alguns dos alunos possuem, os demais informaram que esse tipo de informação não foi repassado pela escola ao mesmo ou que não sabiam informar pois a maioria não tinha laudo médico. P3 disse "não sei informar pois a maioria não possui laudo médico".

$\mathrm{Na}$ escola atual vem crescendo o número de crianças com deficiência, e muitas vezes os educadores não conhecem os tipos de deficiência que as mesmas possuem, a maioria das vezes é porque algumas crianças apesar de aparentar alguma deficiência não possuem laudo comprovando e identificando sua deficiência, mais também acontece do educando procurar a coordenação da escola para saber e o mesmo não obter respostas, ou por resistência da coordenação em procurar os dados dos alunos ou até mesmo por não saber informar.

Antes do aluno ser recebido é necessária uma integração, tanto para os professores como para os demais profissionais que atuam no ambiente escolar, um acompanhamento especializado para lidar com os alunos com deficiência sem receio algum de constrangê-los ou excluí-los e assim transmitir confiança e segurança a este novo membro escolar (Santos \& Ferrete, 2021).

Para os professores poderem trabalhar as deficiências desses alunos, primeiro é necessário conhecê-los, identificar suas deficiências para poder trabalhá-las, Uliana e Souza (2021), relata que é necessário antes de tudo o professor conhecer o seu aluno, entender quais são suas necessidades iniciais, conhecer sua história e seu conhecimento de mundo, ou seja, tentar assimilar o que a criança já sabe para que o educador possa iniciar um trabalho social e pedagógico com o aluno.

Quando questionados sobre quais as principais dificuldades que eles percebem/sentem para incluir o aluno com deficiência no cotidiano escolar, as respostas dos docentes foram variadas e estão transcritas a abaixo:

Pl Estrutura física, á se falam em salas adequadas a essas crianças, porém não há equipamentos e atividades necessárias a essa demanda.

P2 Espaço inadequado, a sala do AEE é muito pequena. 
P3 Falta de formação para os professores.

P4 Pessoas capacitadas para trabalhar as deficiências dessas crianças.

P5 Recursos ainda são insuficientes para atender a demanda total da escola.

P6 Falta à colaboração/apoio familiar e negligencia dos responsáveis, o que leva à falta do laudo médico, em alguns casos.

P7 Falta de material adequado para se trabalhar as deficiências, como material lúdico.

P8 Falta um cuidador/auxiliar capacitado e preparado.

P9 e P10 Não respondeu essa questão.

Com essas respostas, entende-se que há dificuldades diversas, desde a carência da ajuda profissional em áreas específicas, o que perpetra perceber que mesmo que exista na instituição escolar alguém para atender à pessoa com deficiência, a mesma não está qualificada. A indicação nesse município ainda é política, mesmo existindo no quadro dos funcionários psicopedagogos que melhor atenderiam a essa demanda. Os problemas incluem também a questão da estrutura física inadequada e limitações nos recursos didáticos e pedagógicos (Viana et al, 2020).

Não é suficiente apenas a matrícula de alunos com deficiência nas classes regulares. É necessárias condições para a operacionalização desse projeto de inclusão, que venha garantir a todos o acesso à aprendizagem por meio de todas as possibilidades de desenvolvimento a que a escolarização oferece.

$\mathrm{Na}$ fala do P6, é pertinente ainda destacar dificuldades com a resistência da família. Ressalta-se que é determinante e essencial a ajuda de todos os envolvidos, especialmente, dos familiares para a aprendizagem de um aluno com deficiência ou não. Além disso, é razoável assegurar que os professores não se sentem confiantes para trabalhar com crianças com deficiência. Os mesmos precisam de capacitação e do apoio de profissionais especializados para ajudar/auxiliar nas intervenções como uma equipe multifuncional.

Uma observação bastante pertinente é em relação ao acompanhamento que essas crianças não têm na escola, com profissionais adequados, como psicopedagogo, fonoaudiólogo, entre outros, que eles necessitam para um melhor desenvolvimento de suas atividades físicas e mentais.

Sobre a proposta de melhoramento na inclusão da pessoa com deficiência, mencionam a formação e, ao longo dela, seja na graduação ou em formações continuadas, para uma preparação específica a fim de atender a pessoa com deficiências. $\mathrm{O}$ aluno com deficiência necessita de estratégias didático-pedagógicas diferenciadas para seu pleno desenvolvimento.

Quando se questionou sobre as sugestões que os professores dariam para melhorar a inclusão e a aprendizagem dos alunos com deficiência na atividade escolar, as respostas dadas foram as transcritas:

P1 Materiais disponíveis a cada necessidade; profissionais capacitados; pessoas mais comprometidas famílias/escolas/sociedades.

P2 Formação para os professores; material didático especifico para cada criança obedecendo o ritmo de aprendizagem.

P3 Capacitação constante dos professores para o melhor atendimento dos alunos.

P4 Que a famílias aceitassem nossas indicações para tratamentos e terapias.

P5 As escolas devem fornecer recursos e capacitação dos professores para que atendam às necessidades específicas desses alunos, com professores preparados e profissionais especializado.

P6 E necessário a implementação de projetos governamentais, focando na melhoria dos espaços destinados ao atendimento especializado e da disposição de melhores recursos materiais. E principalmente a capacitação dos 
profissionais que atuam na área, tendo em vista que apenas o que foi visto na graduação dos professores da rede regular não é suficiente para se trabalhar com alunos portadores de deficiência.

P7 Professores capacitados para trabalhar as necessidades; material lúdico.

P8 Formação profissional para os professores; profissionais para apoio pedagógico em sala de aula (cuidadores/mediadores); disponibilidade de materiais didáticos.

P9 Apoio e parceria com uma equipe multifuncional, uma preparação coletiva e dinâmica para dar suporte e assim conseguir de fato incluir esses alunos na sala de aula.

P10 Capacitação para os professores; melhores estruturas físicas.

Diante dos dados e sugestões de todos os professores, compreende-se que novamente é gerado, entre eles, o anseio pelo apoio mais eficaz de profissionais especializados na área, como médicos, fisioterapeutas, fonoaudiólogos, assistentes sociais, psicólogos e/ou psicopedagogos, de maneira que fica evidente a incerteza dos professores, que não se sentem aparelhados para atender a alunos com deficiência. Os professores abordam em suas respostas, de maneira geral, uma preocupação com a questão da preparação profissional para se trabalhar com os alunos portadores de necessidades especiais, eles mencionam a formação e, ao longo dela, seja na graduação ou em formações continuadas, para uma preparação específica a fim de atender os alunos com deficiências.

Ainda há muito para se fazer, pois realmente a formação do professor não é coerente para se trabalhar com a inclusão, enquanto isso a pedagogia da diversidade precisa ser vista como uma pedagogia que seja auxiliadora, onde as práticas pedagógicas precisam ser repensadas e modificadas, dependendo da criatividade de cada professor, o modo com o qual desenvolverá seu projeto com a sala, de forma a incluir a todos, através de um planejamento flexível para novas adaptações.

É também importante que essa formação não seja voltada apenas para os professores, como também para todos os profissionais da área da educação na escola, onde os centros de apoio, por sua vez, também farão o seu papel, disponibilizando profissionais especialistas, como fonoaudiólogo, terapeuta ocupacional, psicopedagogo, psicólogo, entre outros (Cardoso et al, 2021).

Um ponto bastante falado pelos professores é em relação a falta de material adequado para se trabalhar com as crianças portadoras de necessidades especiais de acordo com o tipo de deficiência de cada uma, a maioria dos professores afirmaram que a escola não dispõe de material adequado para se trabalhar com esses alunos.

Cabe ressaltar a resposta do P9, que frisa a importância da equipe multifuncional, pois o professor e até mesmo os familiares, são os principais responsáveis pela educação escolar da criança ou do jovem. Sentem-se receosos diante da nova situação para a qual não se encontram preparados para administrar. Por isso, é tão necessário que se crie uma relação de colaboração e confiança entre a escola e a família, e que haja uma larga comunicação entre ambas.

A inclusão, como um princípio orientador do processo educativo, é imprescindível o comprometimento de todos os membros da equipe: professores, gestores e demais funcionários. Todos devem agir coletivamente para que a inclusão escolar seja concretizada. Nessa perspectiva, não se delega apenas ao professor, estende-se aos diversos profissionais e no planejamento de ações e programas voltados à temática. Esse conjunto deve estar voltado à promoção de um espaço favorável às práticas educativas independentes de ser o aluno com deficiência ou não.

Os alunos com deficiência têm o direito à escolarização, uma educação direcionada à formação completa, sem preconceitos e que reconhece as diferenças, assume o status de cidadão. Para que essa educação aconteça é fundamental a criação de redes de apoio aos educadores com a parceria entre alunos, docentes, gestores escolares, da família e profissionais como os da área de saúde e comissão de apoio à educação inclusiva e social que acompanham as crianças com deficiência.

Durante o momento que estive no campo de pesquisa, como na análise dos dados, percebemos uma variedade de lacunas 
na rotina dessa instituição escolar, a exemplo da falta de um planejamento voltado à questão. Também sentimos a falta de preparo dos docentes para atender essas diferentes especialidades, o que vem acarretar barreiras no desenvolvimento desses alunos com deficiência.

\section{Considerações Finais}

A concepção de inclusão está alicerçada na ideia de educação para todos, dessa forma, ao projetar novas práticas inclusivas para os alunos com deficiência, buscando maneiras de explorar suas potencialidades, é notório que estas novas estratégias, também serviram como novas práticas de ensino aos demais alunos, especialmente àqueles com dificuldades de aprendizagem independente de terem deficiência ou não.

Contudo, é necessário haver maior conscientização da própria sociedade em relação a inclusão social, é preciso compreender que essas pessoas têm direitos como todo cidadão e que esses direitos abrangem estar na escola comum juntamente com os demais, não basta estar expresso em lei, é fundamental entender e aceitar o direito do outro.

Ao término desta pesquisa, que teve como tema central abordar e discutir quais são os desafios encontrados pela inclusão no processo de ensino e aprendizagem e durante a pesquisa bibliográfica, foi possível conhecer o processo histórico da educação inclusiva, sua reorganização e ainda abordar a questão da importância da formação docente na busca de uma educação de qualidade. Diante do perfil do quadro de profissionais apresentado, são pessoas experientes e que estão preocupados com a formação de seus alunos de forma integral.

Sendo assim, pode-se verificar que há uma coerência quanto as respostas dos entrevistados em relação a concepção da escola, pois todos posicionam-se numa postura interacionista, preocupados com a mediação e com a construção do conhecimento de seu aluno. Sabemos das dificuldades encontradas no dia-a-dia de uma escola e que trabalhar com alunos deficientes é um desafio, porém verifica-se que a escola é comprometida com a formação dessas crianças e prima pela qualidade na educação.

É importante enfatizar a experiência humanizada, solidaria e o respeito ao outro, independentemente de suas limitações. A importância da participação escolar, pelo desenvolvimento de cada criança, pela cultura que é resgatada, além da diversidade que está inclusa no contexto escolar- horários a serem cumpridos respeitados (recreio), crianças de diferentes estilos e temperamentos, fazendo assim a troca de situações a aprendizagem e o crescimento humano.

O estudo nos levou a repensar, a prática pedagógica dos docentes de um âmbito geral, de uma forma mais especifica os que possuem em sua turma discentes com deficiência. Diante desta reflexão, surge o questionamento de como tornar a aprendizagem desses alunos justa, inclusiva e significativa frente a tantos desafios, contudo concluímos que é preciso ressignificar o processo de inclusão nas escolas.

Há muito o que ser estudado sobre esse tema, e ainda o que fazer para termos um processo de educação inclusiva e acessível a todos, de forma que possamos atender a demanda escolar de pessoas com deficiência.

A Educação Inclusiva apesar de ser um desafio constante para todos os profissionais da educação e para a sociedade em geral pode sim ser uma realidade em todas as localidades e instituições de ensino, pois a inclusão é um dos princípios fundamentais para a transformação humanizadora desta sociedade do terceiro milênio.

\section{Referências}

Aguiar, L. L. (2021). Inclusão de tecnologias assistivas no processo de ensino e aprendizagem de pessoas com deficiência visual no Brasil no contexto do Objetivo do Desenvolvimento Sustentável 4.

Almeida, A. G., \& Montino, M. A. (2021). Dificuldades Encontradas Pelas Professoras No Processo De Inclusão De Alunos E Alunas Com Deficiência. Multidebates, 5(1), 177-193.

Araújo, F. Z., \& Araújo, M. P. M. (2017). A Criança com transtorno opositivo desafiador nas aulas de Educação Física: pressupostos inclusivos. Linguagens, Educação e Sociedade, 1(37), 190-208. 
Bistaffa, V. D. A., Jorge, V. A., \& Vedovato, M. S. (2021). A Perspectiva Da Inclusão Na Escola De Ensino Regular E O Retrocesso. Simpósio Internacional de Educação e Comunicação-SIMEDUC, (10).

Boldarine, F., R., \& Valadares, F. B. (2018). Nell: uma análise sob a ótica educacional e sociocultural de inclusão. Revista PINDORAMA, 6(06), 17-17.

Brancher, V. R., de Assunção Medeiros, B., \& de Camargo Machado, F. (2019). Caminhos Possíveis à Inclusão I: Educação, Gênero e Ações Afirmativas: Dilemas do Nosso Tempo. Editora Appris.

Branco, J. C. (2021). Escritos sobre Educação e Democracia. Portal de Livros da Editora, 1(7), 233-233.

Brigagão, E. L. (2019). Pesquisa bibliográfica: ampliando horizontes. Revista Saberes Acadêmicos, 2(2), 192-201.

Cabral, S. M., \& Almeida, W. G. (2019). A Inserção De Esportes Adaptados Nos Conteúdos Das Aulas De Educação Física Escolar No Ensino Médio. Educação em Foco, 22(38), 203-222.

Calmon, D. C. D. S. (2018). Acessibilidade: a inclusão de alunos com deficiência na rede pública de ensino.

Canto, C. G. D. S., Nunes, P. O. C., \& Silva Rodrigues, A. C. (2021). O lúdico como ferramenta de aprendizagem de leitura e escrita. Revista eletrônica Pesquiseduca, 13(29), 284-299.

Cardoso, A. A., de Mesquita Taveira, G. D., \& Stribel, G. P. (2021). Educação especial no contexto de pandemia: reflexões sobre políticas educacionais. Revista Teias, 22(65), 510-518.

Cazarotti, M. L. B., \& Ribeiro, L. P. F. (2018). Educação e aprendizagem em indivíduos com Síndrome de Down. Revista Saberes Acadêmicos, 1(2), $221-228$.

Correia, C. S. (2014). O desafio da inclusão no ambiente escolar: um estudo no município de Nova Londrina, PR. Monografia (Especialização em Educação: Métodos e Técnicas de Ensino). Universidade Tecnológica Federal do Paraná, Medianeira, 2014. 37. 45f.

Dias, J. T., \& Leventhal, L. I. (2021). Práticas inclusivas e o Ensino de Inglês: um guia para professores de línguas estrangeiras e educação bilíngue. Editora Dialética.

Estrela, C. (2018). Metodologia Científica: Ciência, Ensino, Pesquisa. Editora Artes Médicas.

Ferreira, P. D., \& Bobato, F. C. (2021). Políticas públicas educacionais com perspectiva inclusiva no Brasil e na Argentina: Educational public policies with an inclusive perspective in Brazil and Argentina. Revista Cocar, 15(32).

Ferreira, P. D., \& Bobato, F. C. (2021). Políticas públicas educacionais com perspectiva inclusiva no Brasil e na Argentina: Educational public policies with an inclusive perspective in Brazil and Argentina. Revista Cocar, 15(32).

França, J. S. (2021). Educação Em Uma Perspectiva Inclusiva Na Escola Estadual Senador Adalberto Sena. Communitas, 5(9), 334-345.

Franco, A. M. D. S. L., \& Schutz, G. E. (2020). Sistema educacional inclusivo constitucional e o atendimento educacional especializado. Saúde em Debate, 43, 244-255.

Kistt, T., \& da Silveira Gonçalves, P. (2021). Notas para problematizar a educação física escolar na inclusão dos indivíduos com transtorno do espectro autista (TEA). Diálogo, (46), 01-12.

Leite, B. S. (2018). Tecnologias no ensino de química: teoria e prática na formação docente. Appris Editora e Livraria Eireli-ME.

Lima, J. F., da Silva, L. G., dos Santos Silva, R., \& da Silva Parentes, M. D. (2020). Um olhar sobre a educação inclusiva no PNE 2014-2024: desafios e perspectivas. Práticas Educativas, Memórias e Oralidades-Rev. Pemo, 2(1), 1-14.

Lima, N. R., \& Barros, A. J. D. S. S. (2017). Procedimentos De Intervenção Nas Práticas Educativas Inclusivas: Desafios Do ProfessoR. Revista Includere, $3(1)$.

Menicucci, T., \& Gomes, S. (2018). Políticas sociais: conceitos, trajetórias e a experiência brasileira. SciELO-Editora FIOCRUZ.

Oliveira, D. D., \& Resende, V. D. M. (2020). Branquitude, discurso e representação de mulheres negras no ambiente acadêmico da UFBA. Bakhtiniana: Revista de Estudos do Discurso, 15, 149-171.

Pimenta, P. R. (2019). Clínica e Escolarização dos Alunos com Transtorno do Espectro Autista (TEA). Educação \& Realidade, 44.

Possa, J. D. B., \& Pieczkowski, T. M. Z. (2020). Desafios docentes para a atuação no Atendimento Educacional Especializado. Revista Educação Especial, 33, $1-23$.

Rebelo, A. S., \& Kassar, M. D. C. M. (2018). Indicadores educacionais de matrículas de alunos com deficiência no Brasil (1974-2014). Estudos em Avaliação Educacional, 29(70), 276-307.

Ribeiro, L. O. M. (2017). A inclusão do aluno com deficiência visual em contexto escolar: afeto e práticas pedagógicas. Revista Educação, artes e inclusão, 13(1), 008-032.

Rocha, J. S., Amorim, A., Ferreira, M. D. C. A., \& Lopes, M. M. (2018). A inclusão escolar de jovens e adultos com deficiências: Ações gestoras necessárias. Brazilian Journal of Education, Technology and Society, 11(3), 506-521. 
Rodrigues, C. M., \& Moreira, J. (2019). As Políticas Educacionais Inclusivas E A Pessoa Com Deficiência. Anais do Seminário de Educação, Conhecimento e Processos Educativos, 3.

Santo, S. R. E. (2017). Formação de professores e inclusão de pessoas com deficiência na educação básica. Cadernos de Pós-graduação, 16(1), 163-188.

Santos, C. V. D. C. G., Silva, E. L., \& de Oliveira, V. M. (2020). Narrativas Políticas Educacionais Inclusivas: Compromisso De Quem, Com Quem E Para Quem? Revista Valore, 5, 63-77.

Santos, L. S., Barbosa, A. S. S., Santana, A. F. S. G., \& Monteiro, L. F. T. (2017). A participação da família no trabalho de reabilitação da criança com microcefalia. Caderno de Graduação-Ciências Biológicas e da Saúde-UNIT-ALAGOAS, 4(2), 189.

Santos, W. L., \& Ferrete, A. A. S. S. (2021). A integração das tecnologias digitais de informação e comunicação no Ensino Remoto Emergencial em JeremoaboBA: The integration of digital information and communication technologies in Emergency Remote Education in Jeremoabo-BA. Revista Cocar, 15(32).

Schneider, E. M., Fujii, R. A. X., \& Corazza, M. J. (2017). Pesquisas quali-quantitativas: contribuições para a pesquisa em ensino de ciências. Revista Pesquisa Qualitativa, 5(9), 569-584.

Silva, E. M., \& de Faria, E. A. (2018). Cidade para todos: a inclusão da pessoa com deficiência intelectual no ambiente urbano brasileiro. Uma análise jurídica. Revista Inclusiones, 128-145.

Silva, I. C. R., Ortega, L. S., Silva, D. L., \& Tiago, F. D. C. P. (2021). Caracterização Da Percepção Ambiental De Estudantes Do Primeiro Ano Do Curso Técnico Do Centro Federal De Educação Tecnológica De Minas Gerais. Educação Ambiental em Ação, 20(75).

Silva, K. B. C., \& Cabral, S. B. (2020). Transtorno do Deficit de Atenção com Hiperatividade-TDAH. Associação Brasileira Do Deficit De Atenção-ABDA. Recuperado de: https://tdah. org. br/wpcontent/uploads/site/pdf/cartilha\% 20ABDA. final\% 2032pg\% 20otm. pdf.

Sousa, C. C., de Castro Lima, F., Melo, N. O., \& Teles, A. S. (2021). Realidades aumentada e virtual no ensino de Ciências para alunos com necessidades educacionais específicas em uma escola pública de Barreirinhas-MA. Research, Society and Development, 10(5), e3910514566-e3910514566.

Souza Arieta, M., \& de Souza Bonelli, S. M. (2018). Escola inclusiva. Caderno Marista De Educação, 10(2), e40263-e40263.

Souza, R. T., \& Miranda, J. C. (2020). Inclusão e permanência escolar das pessoas com deficiência: um panorama das escolas da Zona Urbana do Município de Itaperuna-RJ. Research, Society and Development, 9(5), e149953193-e149953193.

Sunde, R. M. (2018). Inclusão escolar: um desafio entre teoria e prática curricular em Moçambique. Rein-Revista Educação Inclusiva, 2(2), 40-50.

Teixeira, D. C., da Silva Pessoa, D., Dias, E. M., da Cruz Silva, G., Tavares, R., de Arruda, A. A., \& dos Santos, F. M. S. (2020). Educação inclusiva e especial: as contribuições da associação Pestalozzi para a cidade de Codó-MA. Brazilian Journal of Development, 6(5), 32414-32425.

Uliana, M. R., \& de Souza Mól, G. (2021). O uso de caso de ensino sobre estudante com deficiência na formação inicial de professores. Roteiro, 46, e27184e27184.

Viana, M. N. G., de Moura Vituriano, H. M., Marques, W. R., Frazão, A. A. N., Sá, R. M. B., Soares, H. A., ... \& dos Santos Lobato, J. J. (2020). Dificuldades de aprendizagem: um estudo de caso na Escola Municipal Osvaldino José de Sousa. Brazilian Journal of Development, 6(10), 75960-75978.

Vieira, S. F., S., \& Carmo, G. D. S. P. (2017). A Inclusão Das Pessoas Com Deficiência Na Educação Brasileira: Da Exclusão Às Mudanças Na Legislação. Revista Educação, Ciência E Inovação, 2(1), 136-152.

Vieira, S. L., \& Nogueira, J. F. F. (2017). Reformas da educação superior no Brasil: tempo (s) e movimento (s). Revista Lusófona de Educação, 35(35).

Winter, P., \& Monzón, A. J. B. (2020). Língua Portuguesa E Síndrome De Down Nas Séries Finais Do Ensino Fundamental: Letramento E Inclusão. Revista X, $15(7), 163-185$ 